\title{
The Management Innovation Research on Small Micro Enterprise
}

\author{
Yan Wang ${ }^{1, a}$ \\ ${ }^{1}$ Xi'an International University, Xi'an, Shaanxi Province, 710077
}

\section{Keywords: Management, Small Micro Enterprise, Innovation}

\begin{abstract}
Small micro enterprises are important component of Chinese real economy and important channel to attract employment and they are also the main venture platform and growth basis for entrepreneurship. Small micro enterprise to implement management innovation is a critical initiative to enhance the operation quality and promote long-term healthy development. This paper systematically analyzes the main problems existing in the management of small micro enterprises, describes the practical significance for small micro enterprises to implement management innovation and made specific recommendations on how small micro enterprises to implement management innovation on this basis.
\end{abstract}

\section{Introduction}

Management innovation of enterprises is the enterprise introduced the new management, tools, management models and management methods and other elements into the management system and implemented innovation activities based on economic conditions and the development of their own production and management needs. Small micro-enterprise management innovation is simply more changes comply with current events, a series of effective change and innovation in the management philosophy, mechanism model, systems approach, with its flexible mode of operation, in the increasingly fierce market competition, expanding its survival and development. Specifically including two aspects: First, adjust and optimize the relationship between employers and employees of small micro enterprises, and the rights and interests of all parties are fully reflected; the second is by adjusting the organizational structure of enterprises and improve the rules and regulations of enterprises, make rational allocation of the various elements within the enterprise, and play the maximum performance [1].

\section{The Main Problems Existing in the Management of Small Micro Enterprises}

Small micro enterprises are usually in the early stages of enterprise development and belong to the start-up stage due to their smaller size. At this stage, the decision are made primarily by the individual executives, the structure is simple without specification, only the minimum requirements for coordination, communication of information within the organization is mainly based on an informal basis. Due to financial constraints, the strength, experience, and business owners the ability of small micro-enterprise philosophy, institutional and organizational aspects of the existence of structural anomaly is particularly prominent. Main features [2]:

Lack of long-term development philosophy and strategic decisions. At the beginning of small micro enterprises, the enterprise organizational structure management and business philosophy has not really formed. Some newly established businesses, although the quality of the staff and the boss is relatively high, but few can do it at the height of development of the industry to examine their own road traveled and develop a complete business development strategy, which is precisely the enterprises seeking long-term development and eternal prosperity must. As we all know, Sony initially but a small workshop, but when it is a small business, set a long-term strategic objectives, it is because there is this long-term goal of support to Sony and other small companies to distinguish, it was a great success. It can be seen, the lack of long-term development goals and strategic decision-making, is the cause of death of many small micro-enterprise is difficult to grow in. 
Lack of effective management mechanisms. At present there are some generally phenomenon in small micro enterprises: Before companies entering the mature stage, high-level decision-makers tend to give priority attention to the growth of business, emphasis on relatively inadequate management, organizational behavior of individuals tend serious. In mature companies, the sector and the team is the basic unit of organization and operation, the individual can only act by departments, teams and standardized system, individual' behavior must follow the organizational behavior. Most of China's small micro enterprises are in the start-up and growth stage, due to the lack of standardized organization and operation system and management regime, the daily operations of enterprises basically rely on the rule of man, which easily lead to affect individuals in the business management process is very big, personal style, likes and dislikes, emotions and other factors also will affect the operation and management.

Lack of effective incentive mechanism. Enterprises lack effective incentive mechanism, so that employees cannot be expected to tend their own future and interest in the organization, you cannot see the path to achieve their own business vision and objectives; personal centralization will inevitably lead to its opportunistic tendencies in business. When these two phenomena occur simultaneously, companies cannot timely system defects perceived adverse effects. Thus, companies will not be able to take effective measures to encourage the staff to work along the best overall interests of the enterprise direction, or deviate from the corporate interests of employees in the future direction of behavior emerge, enterprises and the lack of effective mechanisms to correct and constraints.

Credit and confidence crisis are serious. Most of the small micro business transactions are cash transactions. Due to lack of credit environment and credit platform, trust also prone to crisis, leading owners do not trust the operators, business owners have to take the lead everywhere. However, executives unavoidably affairs, it cannot effectively cultivate management talent, is not conducive to the integration of the company's human resources to build strength. Moreover, a person's energy is always limited, business owners in transactional work to waste a lot of energy, which is bound to affect the depth of thinking in the corporate strategic level.

\section{The Necessities of Management Innovation for Small Micro Management}

It is beneficial to reduce operating costs and increase economic efficiency for small micro enterprises. Small micro business management innovation, the most important and most immediate purpose is through the effective and rational allocation of factors of production to reduce production and management of costs, improve economic efficiency, to achieve sustainable development of enterprises. Although this goal through many other ways and means to achieve, but innovation is to enhance enterprise content management, long-term and healthy development of an effective and sustainable path. Innovation in all aspects of corporate management is to improve the production and management efficiency and effectiveness as a precondition, no matter which part of the optimization improvements, which make innovation, are intended to improve the competitiveness and efficiency of the efficiency of enterprises, promote enterprise long-term development [3].

It is beneficial to develop and embody the entrepreneurial spirit. From small to big enterprises are developed, but also from the growth of entrepreneurs starting up small micro enterprises, through continuous hard but gradually grow up. Entrepreneurs are special rare social resources and good companies need to have first-class entrepreneurs. As a leading entrepreneur, must have management skills, ability and innovative collaboration capabilities, have to make progress in entrepreneurship and innovation in the management of their own will be able to work in the process of implementing innovative cultivate entrepreneurship. Management tends to accelerate the pace of innovation in the management and ownership separated from each other, which will encourage enterprise resources lie in the excellent hands of managers, for the configuration and use of corporate resources more scientific and reasonable.

It is beneficial to establish scientific management system and mobilize the enthusiasm of the staff. The staff is the fundamental factor in business formation, only the promotion of human 
development to be able to promote the development of enterprises. Whether employees are passionate about the work, whether active, it is an important practical issue to be faced by business managers. Small micro enterprises to implement management innovation, and establish a scientific and humane management system, allowing employees see enterprise development vision and personal goal, so that employees play their own advantages to realize their value, which will greatly mobilize and improve employee enthusiasm and creativity, he threw pay their own talent and hard work.

It is beneficial to the realization of the "homeopathic" development. Management innovation of small micro businesses must adapt to the development of the market, to enhance market competitiveness as the endogenous power to innovate. If you try and innovation activities of enterprises in the development process itself is not carried out in compliance with the laws of the market, cannot adapt to market changes and development, then this innovation is not conducive to business development and growth, there is no practical significance. Small micro enterprises make the management innovation by adapting the market changes and focusing on the long-term benefits in order to achieve "homeopathic" on development.

\section{The Initiatives Proposals for Small Micro Enterprises to Implement Management Innovation}

Update new ideas and regard innovation as the strategic initiatives which directly related to the survival and development of enterprises. Outdated and backward ideas is the biggest obstacle currently small micro business management innovation, it can be said that many small businesses have not yet formed and the environment to adapt to the philosophy and standardized management model. Therefore, small micro business owners should recognize that effective management of innovation to compete in the current market situation, the importance and urgency, establish a "strong management effectiveness" concept. Update business philosophy and management thought and promote management innovation of enterprises from a strategic perspective on the basis of raising awareness [4].

Establish effective mechanisms and create a professional entrepreneurial class. American economist Schumpeter: Innovation is the entrepreneur's most important character. Entrepreneurs are person who with most innovative and influential, they do not stay in a rut and do not follow the track of the circulation loop, often creatively to change this track. The current management of small micro enterprises innovative concept of backward, poor efficiency and lack of good entrepreneurial class are not unrelated. Therefore, to promote small micro enterprise management innovation, business owners must focus on training team with a sense of competition and innovative thinking, to create a leading edge of innovation and leadership management market trends in competitive entrepreneurial class. In this regard, we can learn from the successful experience of developed countries combined with China's national conditions, in separate ownership and management, responsibilities, rights and benefits under the same principle, improve the business incentive and restraint mechanisms, to establish a scientific and impartial professional managers People recruitment and evaluation system, and efforts to make the economic benefits of personal interests and business owners of hooks. In creating an entrepreneurial class, the introduction of competition mechanism should be established camp by the talent market, so entrepreneurial factor of production through market mechanisms to achieve a reasonable configuration.

Strengthen the innovation culture construction and create a good management innovative atmosphere. Small micro enterprises implement management innovation relies on cultural infiltration, the need to build one kind to make progress as one, dares to win corporate culture. For this reason, small micro enterprises should further create an atmosphere of innovation, and foster a strong culture of innovation and lasting values, the formation of a strong sense of identity innovation; establish and improve innovative mechanisms to create a strong driving force for innovation; to increase the propaganda value of innovation ideas, employees in this infection [5].

Accelerate institutional innovation and use institutional innovation to promote business management innovation. Management innovation and system innovation are mutually reinforcing, 
complementary relationship. Small micro-enterprise system innovation to solve the microscopic mechanism of rational allocation of corporate resources elements; management innovation, the solution is to small micro enterprises how to combine internal resources to make it as much real estate out of the question, namely to establish a market-oriented internal organization frame, form a highly efficient operation of the incentive constraint and production operations. Innovation can lay a good foundation for promoting small micro business management innovation, management innovation will inevitably lead to the deepening of enterprise reform, establish and improve rules and regulations and more standardized modern enterprise system.

Optimize innovation organizational structure and further enhance management efficiency. Good management scope and management levels of the design division. Management levels and management rate were reflected from the number of horizontal and vertical characteristics of the organizational structure. Specific design must consider the actual situation of each enterprise organizations the ability to take full account of the lower quality of personnel management, the degree of complexity of the work object, communication efficiency and other factors. To improve work efficiency and achieve business goals as the premise, small micro enterprises can select the most appropriate classification method according to their objectives, conditions, nature and characteristics of operational activities, etc. Clearly defined and design respective mandates. Both properly handle the relationship between centralization and decentralization, but also to improve collaborative relationships between departments at the same level.

Implement people-based management and fully mobilize the enthusiasm of employees. People-based management refers to the small micro enterprises through their management activities, so that the staff's enthusiasm, initiative and creativity into full play, so that the personal development of each employee fully. Small micro enterprises should set up and improve the human resource, regulatory agencies, and established a complete measure employee performance incentive, restraint mechanism and staff training mechanism, to provide staff development opportunities and profitability of space, so that employees can achieve the enterprise from development Vision to appreciate their own value.

\section{Conclusion}

For the range of issues existing in small businesses, the country should increase the support for small micro-enterprise those have the innovation will and innovation ability, encourage enterprises to carry out technological innovation on the basis of management innovation and take the transformation, upgrading and innovation development. Actively guide the small micro enterprises to fulfill their social responsibility, correctly handle the relationship between business and society, enterprises and other enterprises, enterprises and workers, enabling enterprises to obtain long-term stable development in a harmonious environment.

\section{References}

[1] H. J. Zhang, Research on human resources management innovation of small micro enterprises, China Human Resources Development, 6(2010) 48-57.

[2] Y. Wang, Research on the driving force behind entrepreneurial innovation spirit, Shandong Social Sciences. 14(2014) 56-72.

[3] C. Wang. Research on management innovation of small micro enterprise, Hunan Normal University. 12(2009) 56-58.

[4] J. Lin, Current Situation and Countermeasure on SME Management, Market Modernization. 12(2009) 25-34.

[5] Y. Zhang, Consideration for SME innovation, Guangdong Polytechnic Normal University. 14(2012) 58-67. 